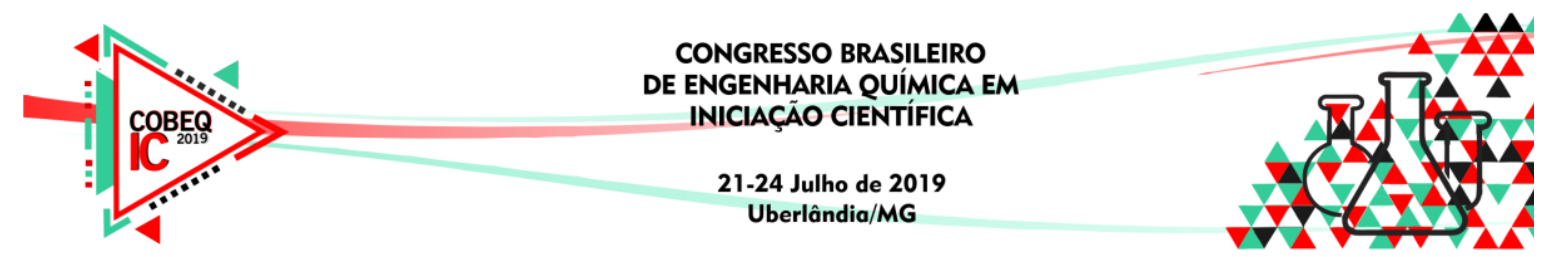

\title{
EFEITO DA DESIDRATAÇÃO EM CAMADA DE ESPUMA NA COMPOSIÇÃO CENTESIMAL DE TALOS E FOLHAS DE CENOURA
}

\author{
G. NUNES ${ }^{1}$, B. S. NASCIMENTO² e R. A. B. LIMA-CORREA ${ }^{1}$ \\ ${ }^{1}$ Universidade Federal de Lavras, Departamento de Engenharia \\ ${ }^{2}$ Universidade Federal de Lavras, Departamento de Ciência dos Alimentos \\ E-mail para contato: gabrielanunes818@gmail.com
}

\begin{abstract}
RESUMO - Os problemas enfrentados na sociedade atual demandam uma maior atenção em relação ao aproveitamento integral de alimentos, a fim de tornar mais nutritiva a dieta da população. Dessa forma, este trabalho tem por objetivo avaliar o efeito da secagem em camada de espuma na composição centesimal de folhas e talos de cenoura em diferentes temperaturas $\left(50,60\right.$ e $\left.70^{\circ} \mathrm{C}\right)$. Para a desidratação, a polpa de folhas e talos foi convertida em espuma pela adição de 10\% de Emustab $(\mathrm{m} / \mathrm{m})$ e agitação. Os ensaios de secagem foram conduzidos em estufa de convecção forçada e os pós foram submetidos a análises de umidade, extrato etéreo, proteína bruta, fibra bruta e cinzas, sendo a fração glicídica obtida por diferença (100 valores das demais frações). A variação na temperatura do ar de secagem de 50 para $70{ }^{\circ} \mathrm{C}$ não influenciou significativamente a composição centesimal dos pós. Alterações nos teores de extrato etéreo e proteína bruta foram observados em relação à polpa. Entretanto, os resultados mostram que os teores de fibra bruta, cinzas e fração glicídica dos pós desidratados não sofreram alterações significativas.
\end{abstract}

\section{INTRODUÇÃO}

A cadeia de produção e distribuição de alimentos envolve diversos processos, os quais necessitam de muitos insumos, desde água até combustíveis fósseis. Estimativas apontam que as perdas e o desperdício de alimentos atingem, anualmente, US\$ 1 trilhão de custos econômicos, US\$ 700 bilhões de custos ambientais e US\$ 900 bilhões de custos sociais (Rodrigues, 2017). Este cenário é, portanto, insustentável, uma vez que o mundo enfrenta problemas como a fome, a escassez de recursos naturais e a perda de biodiversidade. Assim, uma alternativa para evitar que mais áreas sejam destinadas à agricultura e à pecuária é incentivar o consumo integral dos alimentos que já são produzidos.

As hortaliças são um tipo de alimento das quais várias partes são desperdiçadas - como folhas, talos e cascas - e existem estudos que apontam que estas partes "não convencionais" são, muitas vezes, tão nutritivas quanto a parte usualmente consumida. No Brasil, o cultivo de hortaliças é expressivo e a cenoura (Daucus carota) é uma das que se destacam. Segundo a CNA (2017), a produção de cenoura no ano de 2016 foi de 752.196 toneladas, em um total de 16.710.024 toneladas de hortaliças analisadas. 


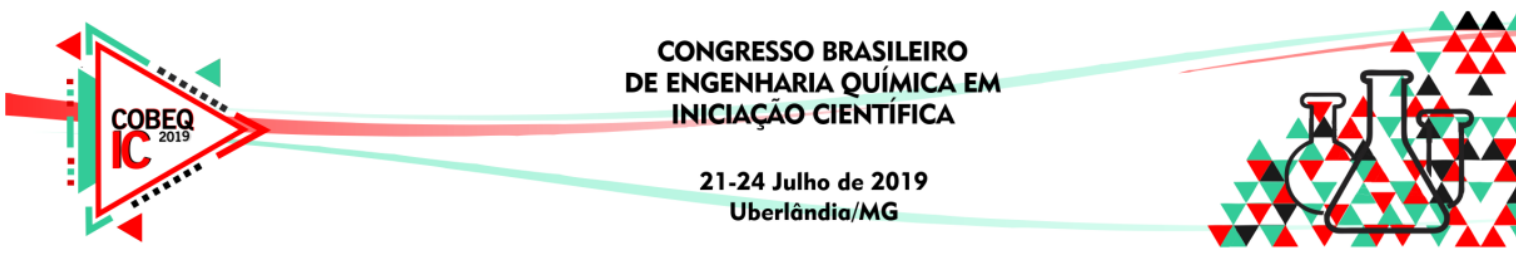

A secagem é uma operação unitária caracterizada pela remoção da umidade de um material através da transferência simultânea de calor e massa, sendo um dos mais antigos e utilizados métodos de conservação de alimentos, com bom custo-benefício (Mujumdar, 2006). A secagem em camada de espuma (foam mat drying) baseia-se na agitação de alimentos líquidos na presença de agentes espumantes, para a incorporação de ar. $\mathrm{O}$ ar incorporado aumenta a área superficial do alimento exposto ao ar de secagem, acelerando a remoção de água e resultando em um produto poroso de alta qualidade (Dehghannya et al., 2018).

Nesse sentido, com o intuito de evitar o desperdício de partes "não convencionais" de hortaliças, o presente estudo objetiva avaliar o efeito da desidratação de folhas e talos de cenoura via técnica de camada de espuma, em diferentes temperaturas. Os produtos secos serão avaliados com relação à sua composição centesimal (umidade, extrato etéreo, proteína bruta, fibra bruta, cinzas e fração glicídica). Espera-se que estes produtos possam ser aproveitados em formulações alimentícias, de modo a fornecer nutrientes à dieta da população.

\section{MATERIAIS E MÉTODOS}

O presente trabalho foi realizado no Laboratório de Operações Unitárias do Departamento de Ciência dos Alimentos da Universidade Federal de Lavras (Lavras, MG). As ramas de cenoura foram adquiridas em feiras locais e higienizadas com hipoclorito de sódio anteriormente ao uso. Em seguida, foram processadas em centrífuga para sucos, obtendo-se um líquido (chamado de "polpa"), que foi congelado para armazenamento. A espuma foi preparada por agitação mecânica em batedeira doméstica ( $\mathrm{t}=10 \mathrm{~min}$ ), adicionando-se $10 \%$ (em massa) de Emustab (Selecta) à polpa. Informações relativas à escolha do tipo e concentração do aditivo e do tempo de batimento da espuma podem ser encontradas em Nunes et al. (2018). Os ensaios de secagem foram realizados em estufa de convecção forçada, nas temperaturas de 50,60 e 70 ${ }^{\circ} \mathrm{C}$. Os pós de folhas e talos de cenoura desidratados em diferentes temperaturas foram caracterizados quanto ao seu valor nutritivo, por meio da realização de experimentos, em duplicata, para a determinação da composição centesimal segundo os procedimentos descritos pela AOAC (1990).

A umidade dos pós foi determinada pelo método gravimétrico, submetendo-se os materiais à estufa a $105^{\circ} \mathrm{C}$ por $24 \mathrm{~h}$. O extrato etéreo foi determinado pelo método de "Soxhlet" a quente, utilizando éter de petróleo como solvente. A matéria seca e desengordurada remanescente desta análise foi utilizada nos próximos experimentos. Para determinação de proteína bruta, foi utilizado o método de "Kjeldahl", cujo princípio está na quantificação do nitrogênio presente na amostra. Nesse caso, o valor de 6,25 foi utilizado como fator de conversão do teor de nitrogênio total em proteína. Empregou-se o método gravimétrico para a determinação da fibra bruta, por meio da digestão da amostra em meio ácido. As cinzas foram quantificadas pelo método gravimétrico, incinerando-se a amostra em mufla, a $550{ }^{\circ} \mathrm{C}$. Finalmente, obteve-se a fração glicídica (extrato não nitrogenado) por diferença, de acordo com a Equação (1), utilizando-se os valores médios das demais frações para o cálculo:

$$
\% \text { Fração Glicídica }=100-(\% U+\% E E+\% P B+\% F B+\% C)
$$




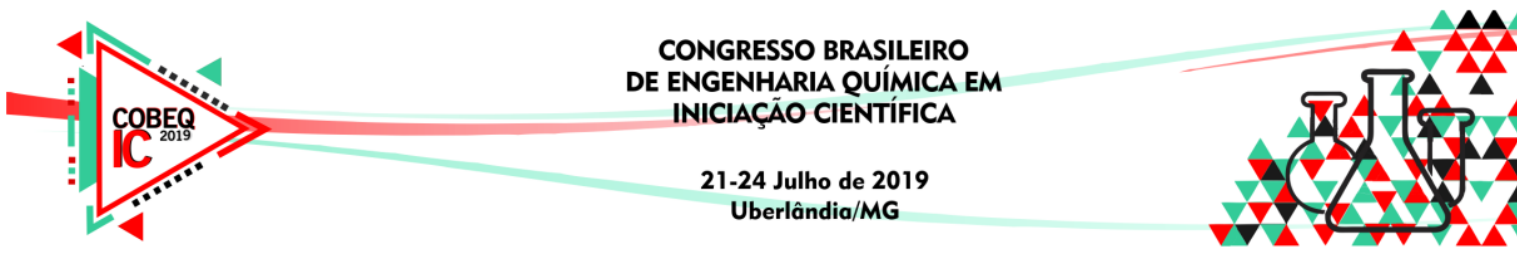

\section{RESULTADOS E DISCUSSÃO}

Na Tabela 1 são apresentados os resultados obtidos para a composição centesimal dos pós de folhas e talos de cenoura desidratados nas diferentes temperaturas. Os resultados anteriormente encontrados na análise centesimal da polpa (Nunes et al., 2019) foram incluídos na Tabela 1 para comparação. É possível observar que os teores de umidade encontrados para os pós foram próximos, entre 5,79 e 10,57\% (b.u.), e mostram que a secagem em camada de espuma foi efetiva na redução de umidade, uma vez que o valor obtido para umidade inicial da polpa foi de 92,19\% (Nunes et al., 2019). Na Figura 1 podem ser vistas imagens da polpa de folhas e talos de cenoura, bem como dos pós secos em todas as temperaturas investigadas, e devido à grande diferença entre os teores de umidade da polpa e dos produtos secos, optou-se por realizar as comparações dos valores obtidos nas demais análises - extrato etéreo, proteína bruta, fibra bruta, cinzas e fração glicídica - com base em matéria seca.

Tabela 1 - Valores médios da composição centesimal da polpa de folhas e talos de cenoura e dos pós obtidos em diferentes temperaturas.

\begin{tabular}{|c|c|c|c|c|c|c|}
\hline \multirow{2}{*}{$\begin{array}{c}\text { Temperatura } \\
\left({ }^{\circ} \mathrm{C}\right)\end{array}$} & \multirow{2}{*}{$\begin{array}{c}\text { Umidade } \\
\text { (b.u.) }(\%)\end{array}$} & $\begin{array}{c}\text { Cxtrato } \\
\text { téreo }\end{array}$ & $\begin{array}{c}\text { Proteína } \\
\text { bruta }\end{array}$ & Fibra bruta & Cinzas & $\begin{array}{c}\text { Fração } \\
\text { glicídica }\end{array}$ \\
\hline \hline Polpa $^{*}$ & $92,19 \pm 0,14$ & $1,52 \pm 0,19$ & $21,90 \pm 0,41$ & $2,29 \pm 0,04$ & $22,52 \pm 0,75$ & 51,78 \\
\hline 50 & $10,57 \pm 0,12$ & $22,15 \pm 0,77$ & $11,14 \pm 0,02$ & $1,41 \pm 0,98$ & $18,86 \pm 0,52$ & 46,44 \\
\hline 60 & $5,79 \pm 0,54$ & $21,07 \pm 1,48$ & $11,17 \pm 0,34$ & $1,52 \pm 0,13$ & $18,66 \pm 0,03$ & 47,58 \\
\hline 70 & $7,47 \pm 0,33$ & $20,39 \pm 0,91$ & $14,95 \pm 0,22$ & $1,95 \pm 0,67$ & $18,62 \pm 0,00$ & 44,09 \\
\hline
\end{tabular}

*Nunes et al. (2019).

Figura 1 - Polpa de folhas e talos de cenoura e pós desidratados em diferentes temperaturas.

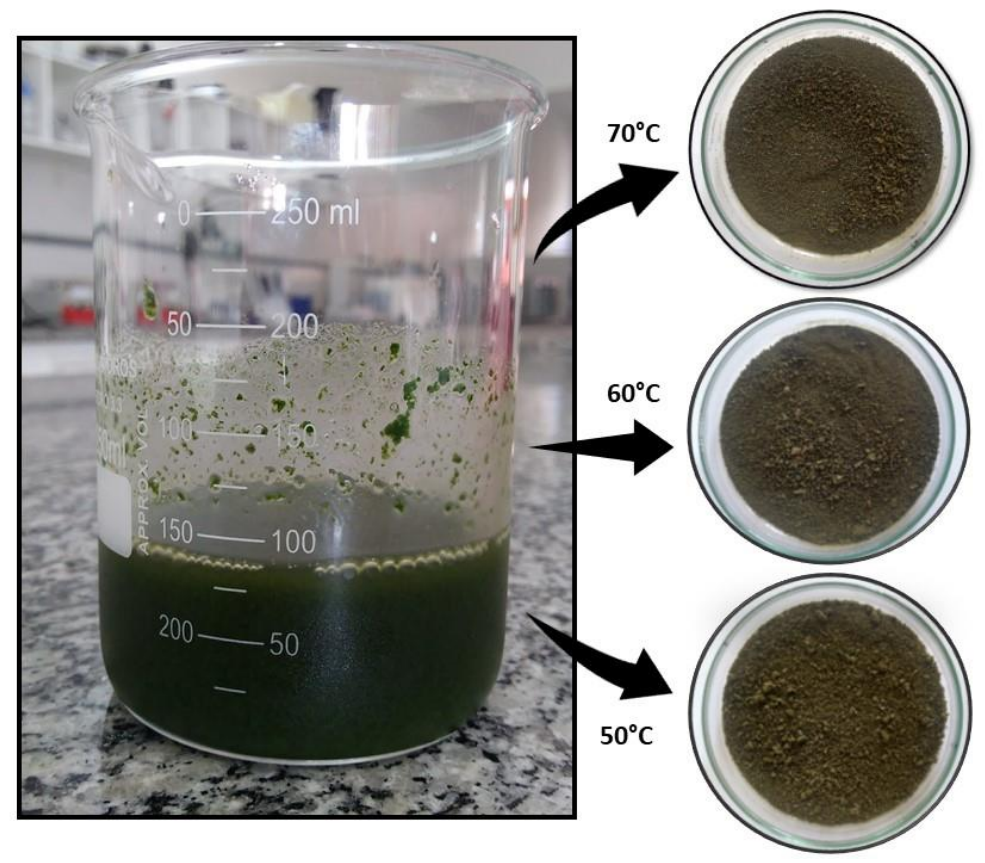

De maneira geral, percebe-se que a variação na temperatura do ar de secagem $\left(50-70{ }^{\circ} \mathrm{C}\right)$ não influenciou consideravelmente os resultados obtidos para as frações que compõem a análise 


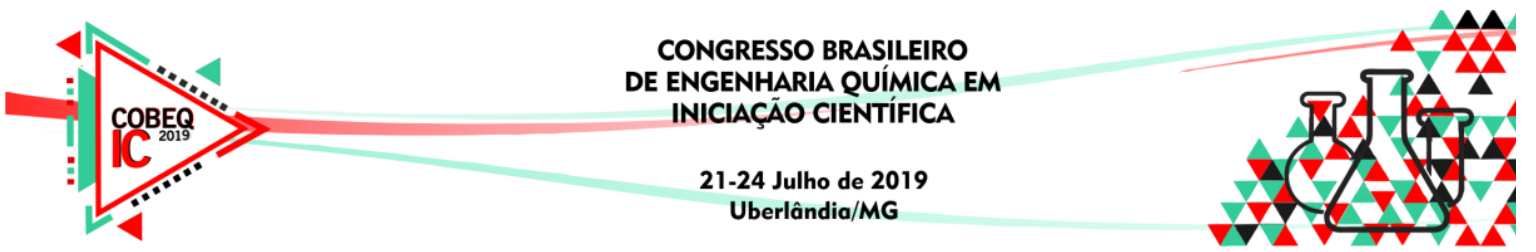

centesimal (grande parte das variações se encontram dentro da faixa de desvios), fato que também foi observado por Franco et al. (2016), ao estudar pós de suco de yacon obtidos por foam mat drying. Entretanto, ao se comparar os resultados aqui obtidos para a composição dos pós com os resultados anteriormente relatados por Nunes et al. (2019) para a polpa de folhas e talos de cenoura é possível notar alterações que podem ser atribuídas à adição do emulsificante e ao processo de secagem em si.

O extrato etéreo é a porção lipídica do material e costuma ter valores baixos para vegetais. Os pós de folhas e talos de cenoura apresentaram teores de extrato etéreo entre 20,39 e 22,15\% em base seca, em comparação com 1,52\% (b.s.) para a polpa de folhas e talos de cenoura (Nunes et al., 2019). Acredita-se que o aumento no teor de lipídeos da polpa para os pós seja devido à adição do Emustab, uma vez que este é um emulsificante composto, em sua maior parte, por monoglicerídeos de ácidos graxos destilados.

Já o teor de proteína bruta, que nos pós variou de 11,14 a 14,95\% (b.s.), mostra-se inferior ao que foi relatado por Nunes et al. (2019) para a polpa (21,90\% em base seca). Essa redução provavelmente foi causada por um processo de desnaturação das proteínas presentes na polpa, em função da exposição do material ao ar quente, uma vez que os ensaios de secagem duram entre $270 \mathrm{~min}$, para a temperatura de $70{ }^{\circ} \mathrm{C}$, e $720 \mathrm{~min}$, para a temperatura de $50{ }^{\circ} \mathrm{C}$.

Os teores de fibra bruta, cinzas e fração glicídica dos pós apresentaram ligeiras alterações em relação aos valores reportados por Nunes et al. (2019) para a polpa, que foram iguais a 2,29, 22,52 e $51,78 \%$, respectivamente. Assim, é possível concluir que o processo de secagem foam mat não afetou de forma significativa os teores iniciais desses grupos de substâncias. De fato, o emulsificante utilizado não é composto por fibra alimentar, não sendo esperado um aumento nos teores de fibra bruta relatados para a polpa. No entanto, o Emustab é composto, entre outros grupos, por carboidratos e sódio, mas a adição desse aditivo não causou alterações consideráveis nos teores de fração glicídica e cinzas dos produtos secos. Outra explicação plausível seria que os possíveis aumentos nos teores de fração glicídica e cinzas, em função do aditivo, não tenham sido percebidos devido a perdas desses compostos durante o processo de secagem.

\section{CONCLUSÃO}

A secagem em camada de espuma mostra-se eficaz para a desidratação de folhas e talos de cenoura, reduzindo a umidade de forma significativa $(\leq 10,57 \%$ b.u.) e preservando, em grande parte, a composição centesimal do material. $\mathrm{Na}$ faixa analisada, a variação na temperatura do ar de secagem não teve influência significativa sobre a composição centesimal dos produtos secos. São observadas alterações em comparação com a análise centesimal realizada para a polpa de folhas e talos de cenoura. Houve um aumento considerável no teor de extrato etéreo, que acredita-se ser resultado da incorporação do Emustab à polpa. $\mathrm{O}$ teor de proteína bruta foi reduzido, provavelmente devido à desnaturação de proteínas da polpa pela exposição às temperaturas de secagem. Já os teores de fibra bruta, cinzas e fração glicídica dos pós apresentaram ligeiras alterações em relação ao que foi reportado para a polpa. Ante o exposto, os pós de folhas e talos de cenoura desidratados por camada de espuma mostram-se promissores para aplicação em formulações culinárias, a fim de se aproveitar os nutrientes presentes em sua composição. 


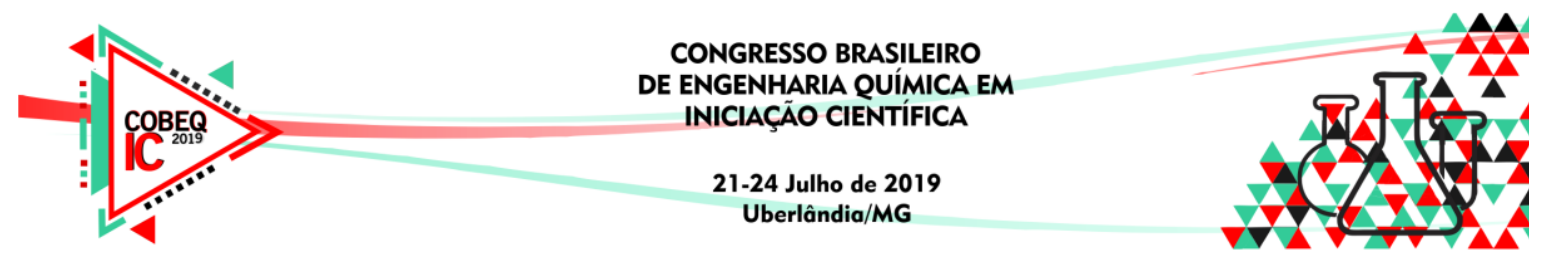

\section{NOMENCLATURA}

$U=$ Umidade em base úmida (\%)

$E E=$ Extrato etéreo em base úmida $(\%)$

$P B=$ Proteína bruta em base úmida $(\%)$

$F B=$ Fibra bruta em base úmida $(\%)$

$C=$ Cinzas em base úmida $(\%)$

\section{REFERENCIAS}

ASSOCIATION OF OFFICIAL ANALYTICAL CHEMISTS - AOAC. Official methods of analytical of the Association of Official Analytical Chemists. 15 ed. Washington, v.2, 1990.

CONFEDERAÇÃO DA AGRICULTURA E PECUÁRIA DO BRASIL - CNA. Mapeamento e quantificação da cadeia produtiva das hortaliças. Brasília: CNA, 2017.

DEHGHANNYA, J.; POURAHMAD, M. GHANBARZADEH, B.; GHAFFARI, H. Heat and mass transfer modeling during foam-mat drying of lime juice as affected by diferente ovalbumin concentrations. Journal of Food Engineering, v. 238, p. 164-177. 2018.

FRANCO, T. S.; PERUSSELLO, C. A.; ELLENDERSEN, L. N.; MASSON, M. L. Effects of foam mat drying on physicochemical and microstructural properties of yacon juice powder. LWT - Food Science and Technology, v. 66, p. 503 - 513, 2016.

MUJUMDAR, A. S. Some recent developments in drying technologies appropriate for postharvest processing. International Journal of Postharvest Technology and Innovation, v.1, p.76-92, 2006.

NUNES, G.; NASCIMENTO, B. S.; LIMA-CORRÊA, R. A. B. Avaliação da secagem em camada de espuma no aproveitamento de folhas e talos cenoura. XXII Congresso Brasileiro Engenharia Química. São Paulo: Editora Blucher, v.1. p. 662 - 665, 2018.

NUNES, G.; NASCIMENTO, B. S.; LIMA-CORRÊA, R. A. B. Análise centesimal da polpa de talos e folhas de cenoura visando posterior desidratação em camada de espuma. V Congresso Mineiro de Engenharia de Alimentos. Lavras - MG. 2019.

RODRIGUES, P. Os desperdícios por trás do alimento que vai para o lixo. Embrapa Hortaliças. 2017. Disponível em: <https://www.embrapa.br/busca-de-noticias//noticia/28827919/os-desperdicios-por-tras-do-alimento-que-vai-para-o-lixo〉. Acesso em 17 mar. 2018. 